Schlungbaum

Medizinische Strahlenkunde 



\title{
Medizinische Strahlenkunde
}

Eine Einführung in die physikalischen, technischen und biologischen Grundlagen der medizinischen

Strahlenanwendung für Mediziner, medizinisch-technische Radiologieassistentinnen und -assistenten

\author{
von \\ Werner Schlungbaum \\ unter Mitarbeit von \\ H. Griszat und R. Krüger
}

6. neubearbeitete Auflage

mit einem Anhang Einstelltechnik

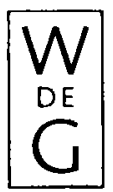

Walter de Gruyter · Berlin · New York 1979 
Professor Dr. med. Werner Schlungbaum

Chefarzt der Strahlenabteilung des

Städtischen Krankenhauses Spandau, Berlin

unter Mitarbeit von

H. Griszat

Leitender technischer Radiologieassistent

Dr. Ing. R. Krüger

Physiker am Krankenhaus Spandau

Dieses Buch enthält 203 Abbildungen, 1 Farbtafel

und zahlreiche Abbildungen im Anhang

1. Auflage: 1959

2. Auflage: 1963

3. Auflage: 1967

4. Auflage: 1970

5. Auflage: 1973

6. Auflage: 1979

\section{CIP-Kurztitelaufnabme der Deutschen Bibliothek}

\section{Schlungbaum, Werner:}

Medizinische Strahlenkunde : e. Einf. in d. physikal., techn. u. biolog. Grundlagen d. med. Strahlenanwendung für Mediziner, med.-techn. Radiologieassistentinnen u. -assistenten / von Werner Schlungbaum. Unter Mitarb. von H. Griszat u. R. Krüger. - 6., neubearb. Aufl. mit e. Anh. Einstelltechnik, - Berlin, New York : de Gruyter, 1979.

ISBN 3-11-007207-6

(c) Copyright 1979 by Walter de Gruyter \& Co., vormals G. J. Göschen'sche Verlagshandlung, J. Guttentag, Verlagsbuchhandlung Georg Reimer, Karl J. Trübner, Veit \& Comp., Berlin 30. Alle Rechte, insbesondere das Recht der Vervielfältigung und Verbreitung sowie der Übersetzung, vorbehalten. Kein Teil des Werkes darf in irgendeiner Form (durch Photokopie, Mikrofilm oder ein anderes Verfahren) ohne schriftliche Genehmigung des Verlages reproduziert oder unter Verwendung elektronischer Systeme verarbeitet, vervielfältigt oder verbreitet werden. Printed in Germany.

Satz: Walter de Gruyter, Berlin. Druck: Karl Gerike, Berlin.

Bindearbeiten: Lüderitz \& Bauer Buchgewerbe GmbH, Berlin. 